of medical reience are strongly impresced with the futility of regarding the mind (brain) as a mere unit, or as the reflex, so to speak, of mere consciousness, and look on the mind (brain) as an embodiment of all the faculties-the assemblage of both the intellectual powers and the moral qualities of our being; and that, for the right comprehension of its disordered states, so much must be admitted.

The following quotation from the "Physiological Proem" which precedes the consideration of mental derangement by Dr. Mason Good, in vol. iv of his Study of Medicine, is so much to the point, that I cannot resist the temptation to extract it. "All the powers of the mind are as liable to be affected with diseases, and diseases of various kinds, as those of the body; and either the body or the mind may be enfeebled at the same time in the whole of its powers, in a few of its powers, or in a single power. A sound mind supposes an existence of all the mind's feelings and intellectual powers in a state of vigour, and under the subordination of the judgment, which is designed by nature to be the gorerning and controlling principle; and, thus constituted, the mind is said to be in a state of order and arrangement. It often happens that this order or arrangement is slightly broken in upon by natural constitution, or by some corporeal affection; but so long as the irregularity does not essentially interfere with the mental health, it is no more attended to than slight irregularities or disquietudies of the body; yet, whenever it becomes serious and complicated, it amounts to disease, and the mind is said, and most correctly so, to be deranged and disordered." By "the mind's feelings and intellectual powers", Good evidently recognises not only the brain as the organ of the mind, so to speak, but the latter named " as an embodiment of all the faculties - the assemblage of both the intellectual powers and the moral qualities of our being", to repeat my own words. Whatever may be the specific views of medical writers concerning the origin or source of "emotional sensibility", by which is meant the moral feelings and affections, and the passions of men, the majority doubtless favour that opinion which ascribes the same to the brain, though to a part or parts of the organ distinct from that or those which preside over, or are connected with, "consciousness". According to Dr. Noble, the optic thalami constitute the seat of the "emotions"; from which riew of the case this gentleman would imply that, in every case of insanity, involving the said "emotional sensibility", as evinced in grief, joy, hope, fear, pride, vanity, affection, and so on, one or both of these structures is organically affected. However, if it be admitted as a psychical fact that the passions, like the intellect, are energetic in proportion to the development of the brain; that it is only in the superior classes of animals (those in which the brain is well developed) that we meet with evident indications of love, friendship, courage, ambition, anger, jealousy, hatred, fear, joy, grief, etc.-then must we infer that in every case of disease, involving any undue manifestation or perverted action of the said moral feelings or "passions", the brain has undergone some change from its normal state, and that such change is the immediate cause of insanity.

RECAPITULATION. I have, then, after some general and introductory remarks, endeavoured to show you the importance of a knowledge of the structure and uses of the brain, and its direct application and reference to the subject of insanity. The size and form of the whole brain have been shown to modify the psychical phenomena, both in health and in disease ; and the relative proportion of individual parts has been demonstrated as exerting much influence on the indications of mental disorder in many of its various forms. Definitions of insanity have been mentioned, and their merits considered; various forms of the disease have been explained; and the classifications adopted by eminent writers have been commented on, with the view of educing those principles which should guide the psychologist in his inquiries, and take the place of the mere words now employed so generally, involving, as they do, not a little ambiguity, and not a few contradictions.

In my next lecture, I shall consider the "Origin of In- sanity", and the signs and symptoms which characterise its principal varieties or forms, etc.

The nature of an individual case of insanity belongs so much to the cause in which it originates, that their consideration may very properly go together; but of this at our next meeting.

Northwouds, Bristol, 1855.

\section{DEATH FOLLOWING RUPTURE OF THE BLADDER FROM A KICK: WITH MEDICO-LEGAL REMARKS.}

By HENRY PORTER, M.D., House-Surgeon to the Peterborough Royal Infirmary.

The following case occurred in the practice of Mr. William George Porter, of Peterborough, with whom I had the pleasure of noticing it. I am induced to publish it partly on account of its comparative rarity, and partly because it is somewhat analogous to a case which occurred some months since on board the Dauntless, lying off Portsmouth; and which was brought very prominently before the public.

Sunday evening, May 27th, 8 P.M. Mr. W. G. Porter was summoned to attend Samuel Brown, aged 35, an agricultural labourer, who was said to have received a severe injury whilst taking part in a fray on the previous erening, outside his village public house. When seen, he was sitting down stairs, complaining of great pain in the abdomen, and inability to pass urine. He stated that, whilst acting as backer to a friend in a fight, he had received a severe blow or kick in the abdomen, from the effects of which he fell to the ground, and lost all consciousness until carried home (a listance), when he gradually recovered his senses, but had been in great pain all night and during the day following, and had passed no urine. He walked up stairs, without assistance. Upon examination, the abdomen was found much distended, especially at the lower part; and the fundus of the bladder being apparently above the umbilicus. A catheter was introduced, but did not seem to go home in the bladder, and but a small quantity of urine escaped, until the man was placed in the erect position, when as much as three and a half or four pints of fluid were drawn off, very highly tinged with blood. He expressed himself as much relieved. There was not much tenderness on the abdomen. The pulse was steady, though rather small; and the bowels had not been relieved. An aperient mixture was ordered to be taken every four hours; warm fomentations to be applied to the abdomen; and one grain of opium, in the form of a pill, to be taken immediately, and to be repeated in four hours, if sleep was not procured.

When seen the following morning, he had slept about three hours, but complained of a good deal of pain. The bowels had not been relieved. The catheter produced about the same quantity of fluid, but with something less of blood in it. The abdomen was not at all tympanitic, nor was there much tenderness, except over the region of the bladder. The man lay on his back, with his legs straight down the bed. The pulse was regular and small, 100. He was ordered to continue the mixture and fomentation.

8 P.x. The patient was much in the same state: he had made several attempts to empty the bladder, but without success. By the catheter, about a pint and a half of urine escaped, less tinged with blood, but with several small coagula. There was no tympanitis; the bowels were still confined. The same treatment was continued: fomentar tions and opium, with castor oil every three hours.

Tuesday, May 29th. He had passed a restless night; and, though he complained of much pain, it was confined to the region of the bladder, and was but very slightly increased by pressure. There was no tympanitis, or other symptom of peritonitis: he lay straight down in bed, and bore the weight of the bed-clothes. The catheter was passed, and about a pint and a half of urine escaped; it was lighter in colour, but contained some clots. A copious enems 
a we weter we giree, which relloved tho bowals. The palco was emall, about 100; the tongue brown; and the contenance anxious.

8 P.I. He was in much the same state. There was no imareseed pain or tenderness since the morning. About a pint of urine escaped through the catheter. The same difficulty was experienced on this, as well as on every former and subsequent occasion, in obtaining any urine without placing the man upright. He was ordered to have brandy; and the opium was repeated.

Wednesday, May 30th, 11 A.M. About 3 A.M. this morning he became worse; bilious romiting set in; and, when seen, he had ejected large quantities of fluid, tinged with green bile. There was perhaps rather more tenderness over the abdomen; but he bore some amount of pressure vithout complaining. The pulse was very small, 120 . He was evidently sinking. He had been out of bed several times during the night, trying to pass his urine. By the catheter, a small quantity, about half a pint, was obtained.

8 P.x. He was pulseless; the extremities were cold. He expired at 1.30 A.M.

Examination of the Body fifteen hours after death. There was a slight bruise externally on the left side, half way between the umbilicus and the anterior superior spinous process of the ilium ; and on cutting through the abdominal muscles, blood was found extravasated into their tissue at the same spot. The small intestines were found distended with gas, and firmly agglutinated with lymph. The omentum was drawn or twisted up into the left hypochondriac region, as is sometimes found in chronic peritonitis. It was noticed that the inflammatory action was chiefly confined to that portion of the small intestines corresponding to the attachment of the mesentery. On examining the bladder, a large aperture was found on its posterior and upper surface, above the reflection of the peritoneum, of sufficient size to admit two fingers; the edges of this opening being somewhat ragged. There was no trace of any previous disease of this organ.

Owing to the presence of friends of the deceased, no more minute examination of the parts could be made.

Remarks. This case appears to me to possess many points of no ordinary interest to the profession-an interest which in such cases is much increased, from the silence which has been observed by all modern writers with regard to injuries of this description. The chief points calling for remark, are-1st, the absence of signs of peritonitis during life, at all commensurate with the amount of inflammatory action observed after death; 2nd, the length of time which elapsed between the receipt of the injury and death; and $3 r d$, the question may arise, whether the rupture was complete at first, or whether the peritoneal coat remaining entire, gave way at a subsequent period.

The usual diagnostic symptoms of rupture of the bladder were absent. If summoned to a person who has met with such an accident, the surgeon would expect, on passing a catheter, to obtain very little, if any urine; there would be intense pain all over the abdomen, aggravated by the slightest pressure; the patient would be collapsed from the moment of receiving the injury, and it might be expected to prove fatal in a much shorter time. There was no sign during life to indicate the amount of inflammatory action going on in the abdomen. This inflammation, however, had assumed more of the form of chronic peritonitis; a state which is not unfrequently observed after death, where it has been entirely unsuspected during life.

Secondly, the length of time between the injury and death bears more especially upon the third point; namely, whether or no the rupture was complete in the first instance; and if, as I am inclined to believe, it was so, we moy learn from this the necessity of the greatest caution in prognosis, in all cases of injury to the abdomen, even whon twenty-four or forty-eight hours pass orer without say urgent symptoms being present.

On the third point, I am inclined to the opinion that the septure was complote st firet, and for these reasons:-
Firct. There was a degree of collapes about the patient from the first, which, though never extrome, was outieient, I think, to warrant this conclusion.

secondly. There was no change in the symptoms, from chronic to acute, which would, I believe, have been the case had the peritoneal coat of the bladder given way sub. sequently to the receipt of the injury.

Thirdly. There was no increased intolerance of pressure, nor any excess of pain, five hours before death, to what there was three days previously.

Fourthly. The rupture was a very large one, and in the situation in which the catheter would pass directly through it into the cavity of the abdomen, and I conceive such a thing by no means impossible, whilst the agglutination of the intestines would prevent general diffusion of the fluid throughout the abdomen.

Fifthly (and this I consider to be very strongly confirmatory of the opinion which I have formed). It was impossible, on the first and on all subsequent occasions, to obtain urine through the catheter until the man was placed in the erect posture.

Petcrborough, Juno 12th, 1855.

\section{PERISCOPIC REVIEW.}

\section{SURGFRY.}

\section{RARE CASES OF DISLOCATION AND FRACTURE.}

EXTEXSIVE FRACTIRE OF THE BONES OF THE CRANIUM.

Dr. J. G. Fr.wniso relates this caso in the Glasgow Mledical Journal, for January 1855.

P. R., aged 43 , a mason, fell from a height of six feet, and was struck on the head by a stone. His skull was fractured round the entire lateral circumference. Beginning at the right parietal bone, the fracture extended through the petrous portion of the temporal, across the base of the skull, through the sella tunica of the sphenoid, then through the left temporal, and across the parietals. The petrous portion of the left temporal bone was necrosed, and the parts of the internal ear were disorganised. The brain and dura mater were healthy. The sinuses were diseased, especially those of the left side, which were blocked up, and surrounded with purulent exudation.

The man lived fifty days, and at last died gradually in a state of stupor. For three weeks, however, though his skull was so extensively fractured, and a portion of the right parietal bone was comminuted and depressed, he retained his intelligence, had no general paralysis, slept, and took his food tolerably well, complained little of pain, and was altogether very free from marked constitutional disturbance. At times after this, he was in a state of stupor or restless bewilderment: but he did not become comatose, or entirely lose intelligence till within two days of his death.

DISLOCATION OF THE LOWER JAW UPWARDS AND BACKWARDS.

A case of this rare injury is recorded by Dr. CroKer KING in the Dublin Hospital Gazette.

On September 3rd, 1551, J. M'T., a boy aged 8 years, fell in attempting to climb over a wall of loose stones, and was struck on the face by a large stone. On lifting him up, his features were seen to be much distorted, and blood flowed from the leftear. Attempts to relieve the patient having proved inefiectual, he was brought into the Infirmary: when the following was his state, seren hours and a half after the accident. The chin was much retracted; the mouth was open, and saliva pourod from it. Articulation was very indistinct. The chin was pointed to the left side, and on pressing it upwards, the patient appeared to suffer much pain, and the mouth could not be closed. The intermal tubercles of the inferior molar fell ontside the external tubercles of the corresponding teeth of the upper jaw; and the lower incisions were at least one inch behind the upper. The line of the lower teeth appeared quite perfect; no irregularity or fracture could be detected; however, in grasping the bone on each side of the symphysis, Dr. King could detect a hinge-like motion, which enabled him to separate the sides of the jes from each other. From these circumstances, Dr. King was led to the diagnosis that the left condyle of the lower jaw had passed upwards and backwards, this displacement being foroured by the separation of the parts of the jaw at the symphyais; the 